\title{
New life cycles for modern ruins
}

\author{
P. Miano ${ }^{1} \&$ G. Aquilar ${ }^{1,2}$ \\ ${ }^{I}$ Department of Architecture, University of Naples Federico II, Italy \\ ${ }^{2}$ Department of Cultures of the Project, IUAV University of Venice, Italy
}

\begin{abstract}
The transformation of modern industrial ruins, "machine-buildings" belonging to a relatively recent past - now devoid of their original meaning and use - allows an argument to be established on the role of the project as the intrusion of a "new life" within these architectures. Topics such as the reuse, recycling and rehabilitation of the productive heritage may be declined through the concepts of novelty and originality: an original re-reading of the pre-existences can produce a new spatial interpretation, capable of generating an authentic innovation, even through limited interventions. Starting from these premises, the proposed reasoning focuses on two projects - both partly realized - meant as the media to clarify the theoretical position assumed: the Washery at the Argentiera in Sassari, intended to accommodate the Mining Museum, and the Mill-Garden at the Zolfara in Tufo, designed to host the Wine Museum. In a time span ranging from the late nineteenth century to the sixties, these productive buildings - related to the mining assets - have had a parallel life: for many years the industrial activities have been completely interrupted and the structures totally abandoned. The "first life" of these buildings - with all their transformations - has been unequivocally concluded, and their "remains" have become an integral part of the landscape. The task of the project is therefore to insufflate a "second life" into these structures: a type of intervention which is not easy to define in synthetic terms, that originates from the pre-existing building and respects the needs of conservation, but does not act just as a restoration or introduction of new functions. The very peculiar spaces of the two complexes are today much more than fragments of their previous lives, and the deciphering of these spatial dynamics becomes the most interesting part of the design work, meant as the key assumption for the idea of the "new" in architecture.
\end{abstract}

Keywords: recycle, modern ruins, machine-buildings, industrial landscape. 


\section{Introduction}

The buildings for production - dotting the territories of the contemporary city, as abandoned shells at the passing of time - stand as an occasion to address new urgencies and renewed meanings, able to put the focus on research and experimentation about new transformation devices for the "old" spaces of industry. These abandoned relicts - testimonies of a recent past - thus provide a chance to urge a reflection on new intervention strategies for the existing architecture, capable of holding together memories and even very challenging innovations. A reflection on the mechanisms of genesis and on the potential transformations and "re-significations" - able of triggering new life cycles into these "modern ruins" [1] - implies the application of an archaeological approach to the contemporaneity, by searching for "new grounds" within the "strata" overlapped or underlying the existing spaces. At the same time, this process may also guide the drawing of tactic directions that should prevent the production of "waste" caused by a new abandonment, which risks to be often even more traumatic, compared to the original dereliction [2].

Most often, these ruins consist of "machine-buildings" [3, 4], architectural structures that once provided specific answers in an industrial and/or mining production cycle [5, 6], but which today do not configure anymore as perfect machines. Rather - to a certain extent - the devices of these no longer functioning machines are still capable of evolving, of assimilating the change, after passing through a long provisional status.

In some cases, these machine-buildings represent the physical permanence of an industrial past, that over a very wide time span had characterized a whole territory and had outlined a type of development which proved to be transitory and unrealistic in the long run.

Therefore, in these territories - although in a contradictory manner - these machine-buildings still represent the fundamental elements for identification and recognition, right because in the past they had determined some specific features, and today - even partially - they still mark out the morphological structure. This role may be attributable to the fact that they hold (a) a position value, related to their historical events and location; (b) a formal value, connected with their articulation and to the materials with which they have been built; and (c) a landscaping value, as - in a more or less accomplished manner - they have been reabsorbed from the naturalistic components, just altered through their realization.

However, they do not necessarily constitute elements of stability. Indeed, their peculiarity stands in the inherent possibility of change that they hold, related to their own nature of "machines", whose functioning have been necessarily updated over time, by accepting the technical innovations that were achieved under a particular manufacturing and productive field.

\section{The first life and the "strategic" abandonment}

Starting from these premises, a reflection about some specific situations - meant as the media to investigate the identified issues - is proposed here. The two case 
studies are settled in very different contexts within the Italian territory, which can be both considered to lie in a condition of crisis: the Laveria (Washery) at Argentiera (Silversmiths) in Sassari (Sardinia) and the Mulino-Giardino (MillGarden) at the Zolfara (Sulfur mine) in Tufo (Campania).

In a time span ranging from the late nineteenth century to the sixties, these machine-buildings - related to the mining assets - have had a parallel life. For many years the industrial activities have been completely interrupted and the structures totally abandoned, even through the removal of important remains of their own history.

The "first life" of these buildings - with all the undergone transformations, and frequently also difficult and dramatic alterations, related to the productive activities - has been unequivocally concluded.

The pictures of the two abandoned buildings - in state of ruins - show some fundamental characters: the Washery, impressive architectural relict that unexpectedly shows up at the sight of those who follow the access road to the sea coast of Argentiera in the town of Sassari (fig. 1); the Mill-Garden, wide isolated building with longitudinal development - of eclectic footprint - in complete neglect, with its main facade arranged along the railway line from Avellino to Benevento (fig. 2).

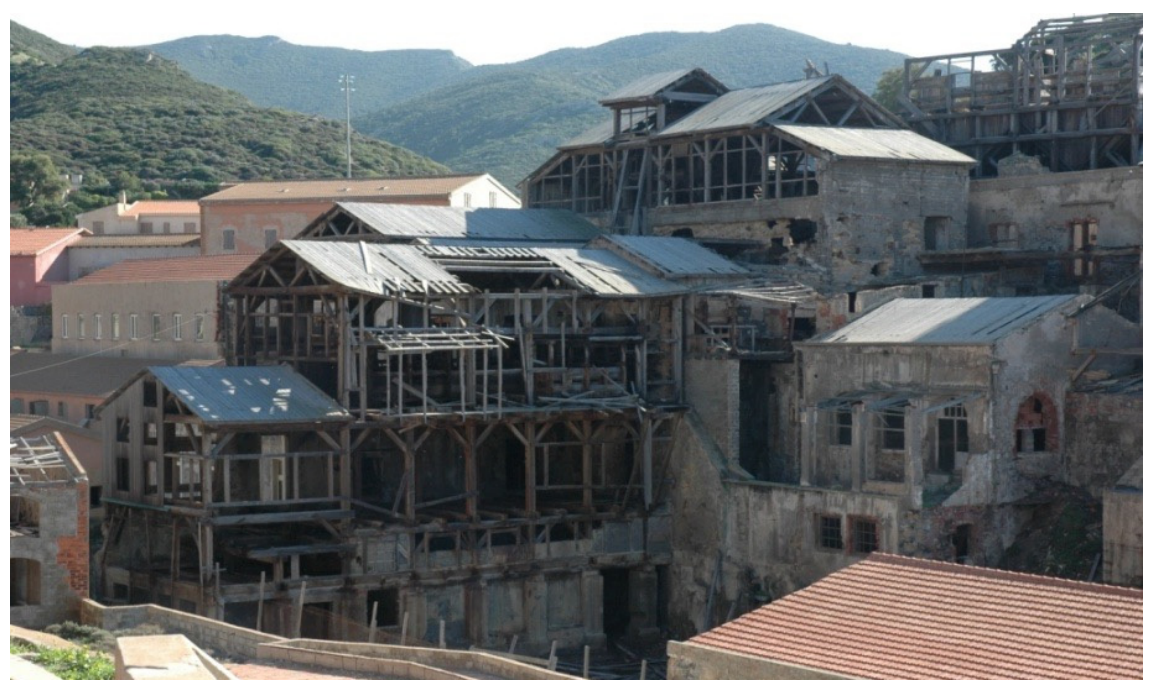

Figure 1: The ruins of the Washery.

Either way - as it was the case also in other situations - a very unique status has been triggered: the "remains" of the two large productive machines have become an integral part of the landscape, thus playing an absolutely dominant role and establishing a condition that makes them difficult to separate from the morphology, the vegetation, and all the other elements of the identity of their place of settlement. 


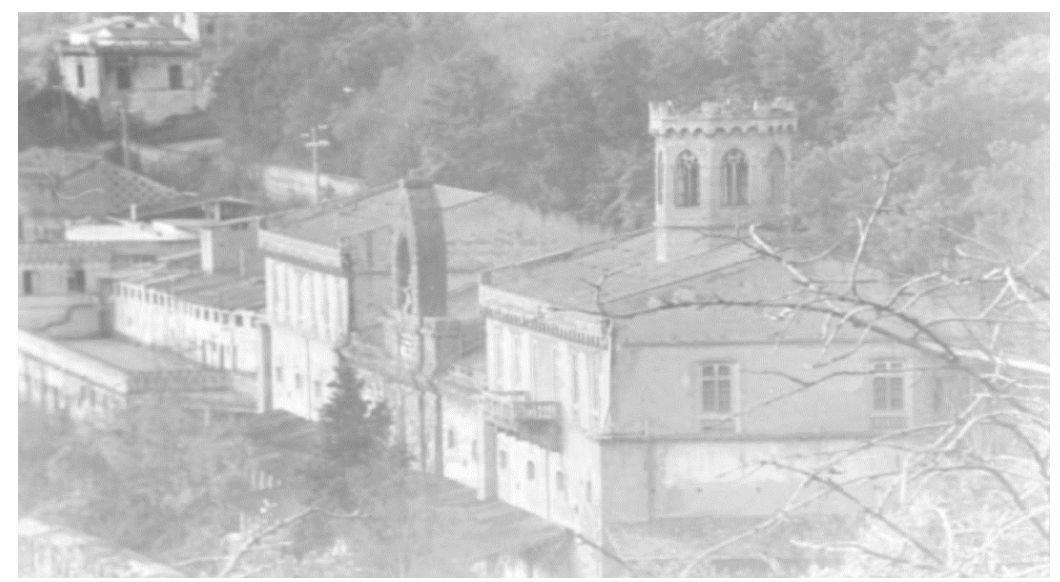

Figure 2: The established image of the Mill-Garden.

At Argentiera, the re-naturalized ruins of the Washery do not stand as insulated objects. Indeed, they interact with the existing natural components, altered and partially cementified (rocky ridges, esplanades). Some "rationalist architectures" of the laborer borough stand among the naturalized remains and the "estranged" natural elements. These artefacts (the movie theatre, the post office, the directional building, the church), also look out of place - in some respects - but they reflect the morphological conditions of the site itself, by virtue of their particular position.

The identity of Argentiera is therefore enclosed unequivocally in the relationship among the mine, the laborer borough, and the landscape, but it is also the result of the most recent failed attempts to transform the area. These efforts were born with the aim to "steal" little volumetric increments or to realize some difficult connection with inadequate means, this way resulting in bulk adjustments - even on the most delicate and representative parts of the village - and then contributing to the degradation of the area (fig. 3).

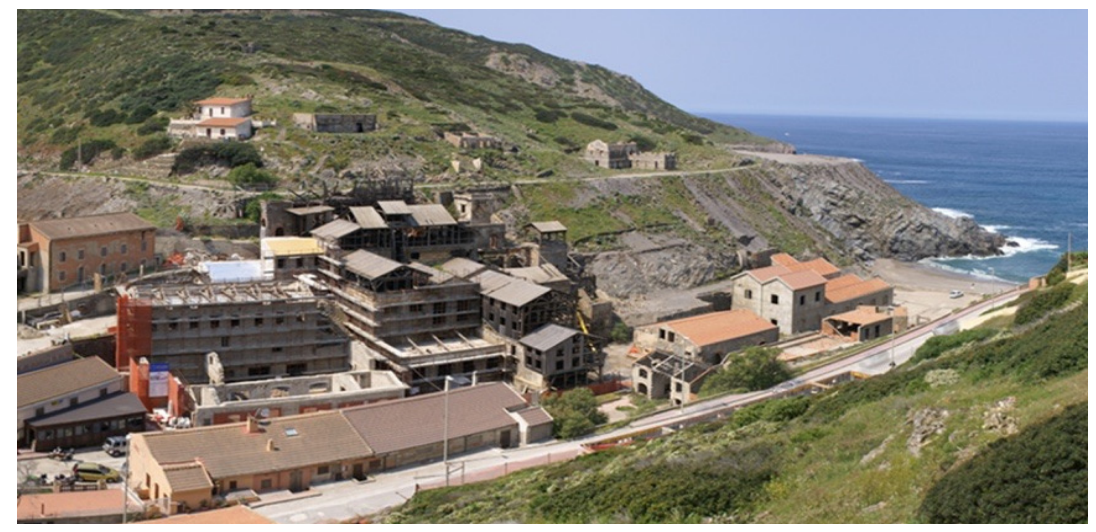

Figure 3: The remains of the Washery within the landscape of Argentiera. 
In Tufo, the images of the Mill-Garden in a state of neglect - particularly the views from the south, that have now become part of the tourist itineraries of Irpinia - focus on the wide building located at the foot of a completely green hill, with unitary, preserved, and recognizable architectural features (fig. 4).

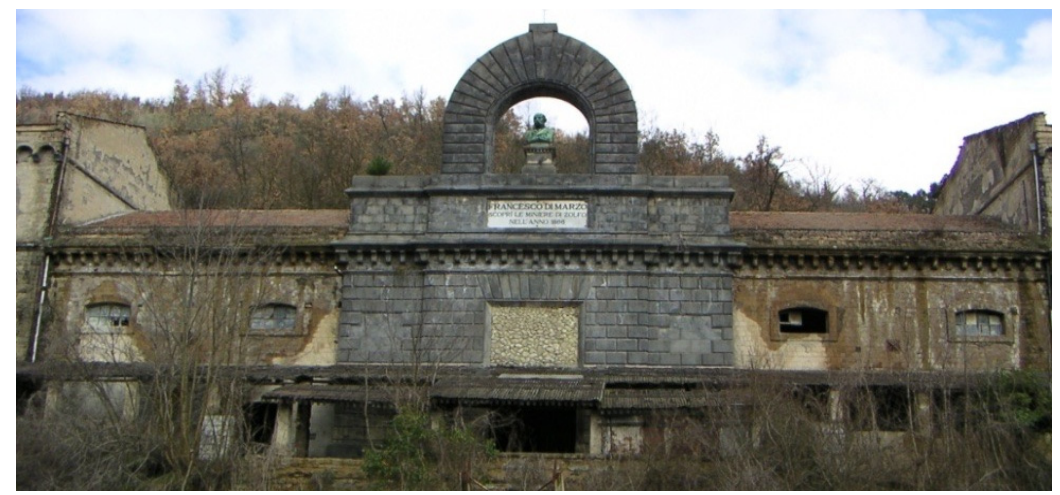

Figure 4: The facade of the Mill-Garden along the railroad.

When approaching the building, it is possible to notice the presence of further building blocks and spaces, which make clearer the articulation of the overall composition of the productive complex.

At the same time - from a closer perspective - also the high level of degradation of the area can be perceived, to some extent further compounded by the new industrial settlements located downstream, the looming danger of water seepage from the rooftops at several points, the perpetrated subtraction of window frames, machineries, furnishings, and the frequent and extremely dangerous fires.

Such conditions - now consolidated for many years - have been challenged by the administrations. After long and complicated events of expropriation or purchase, the public owners have thus planned the retrieval and reuse of the artefacts - meanwhile bound as architectural and landscape heritage - through the addition of new functions. In a certain sense - even if unconsciously - a "strategy of abandonment" seems to have been adopted in these places, that is not at all irrelevant in the current configuration of the two buildings. This "selective" [7] strategic direction leads to wonder not only about what to "preserve", but also what should be "lost", what should be left to oblivion [8] - so that the new use will be able to determine also a new sense - and further about how to "manage the absence" [9]. In this perspective, "it is then not a question of bending the project in terms of process, in order to prevent waste or to boost marginalized areas through the superimposition of new designs and meanings, but rather to produce waste and abandonment strategically, to seek precisely what is often simply a resulting, an unexpected reflex of the project, or which only apparently may seem inaction; substantially to make abandonment a design tool" [10].

Therefore, in both cases of the Washery and the Mill-Garden, the abandonment plays a crucial role, as well as the architectures in state of ruins, in their material substance. 


\section{State of waiting and the second life}

Both buildings have experienced a long phase of "waiting", biding the interventions which could have brought them back to life, but this time of suspension has not been neutral to them. While they were in this state of waiting, these architectures have undergone a slow transition from a "determinate" condition to an "indeterminate", "incomplete", "unfinished" status. In this process, they have gained new value - in terms of beauty, but also of potentiality - so now their need is not simply the definition of a new function, but surely something much more complex and detailed, albeit to be achieved "through minimal shifting, via continuous modifications" [11]. Therefore, in both cases, the task of the project has been to insufflate a "second life" into these structures, a condition of novelty and originality through an open approach, outside of any conceivable preestablished position or solution, in a state of high variability and effective amplitude of the interpretive possibilities. The new life of these machine-buildings - namely the architectural design of their second life - originates from the preexisting artefacts, but does not act just as a restoration. Certainly it deals with the introduction of new functions - although in respect of the needs for conservation - but even this aspect is definitely no means sufficient to define the action to be taken [12]. In describing the reconstruction project for the Carlo Felice Theatre in Genoa by Ignazio Gardella and Aldo Rossi, Vittorio Savi used a very interesting definition: "in order to establish the type of this operation, any entry of the architectural-urban dictionary currently in use is not appropriate (...) rather what is needed is the word deducible from the 'De Re Aedificatoria' by Alberti, the term 'instauratio'. To take the corpse of architecture, to recompose it, to restore it (with critical and constructive additions), to bring the organism back on its feet, to insufflate life" [13]. Then Savi came to the conclusion that the paradigm of the intervention by Gardella and Rossi was the Malatesta Temple in Rimini by Alberti, and no other example of restored building.

The main question is then: how to blow new life into these productive machines, originally arisen and developed through time in response to practical purposes, but now devoid of their original functioning? How to insert new functions into these machines, through which - quoting a synthetic expression by Andrea Branzi - "the city of the future realizes itself in the inner spaces of the contemporary city" [14]?

Indeed - in the history of the two artefacts - there were some stages in which the state of activity was truly important, with continuous and sudden transformations.

The Washery - at the height of its functioning - took an architectural definition which was fuller than the image emerging at present. Even in Tufo - in the late nineteenth century - the owners of the mine had planned the construction of a broad longitudinal machine, that should have been settled along the difference in height between the street and the railway line; however, this program actually comes about only in a limited portion of the structure. Thus it is properly a territorial project, in which the activities of the mine define the very meaning of these places: a landscape of production, that integrate itself with nature. Today, 
the two complexes accommodate peculiarly characterized spaces, representing much more than just fragments of their previous lives.

Therefore the design work finds its most interesting part in the act of the deciphering of spatial dynamics, in which the understanding of the meaning of these buildings - related to mining activities - plays a very significant role.

The Washery is composed of spaces arranged at various altitudes, according to a very close chaining: a proper intertwined sequence of concatenated spaces, among which the independent bodies of the workshops can be distinguished, with their more regular and ordinary setting.

On the other hand, in the case of the Mill-Garden, the prevalence of the "lengthways extension" can be clearly noted. Even this architecture is made up of levels, but it is much more stable and built in a less provisional way. The result is a finite architecture, somewhat rhetorical in the façade towards the railway, articulated into three blocks aggregates along the longitudinal axis, and then followed by further elements which become increasingly less structured, until they merge with the morphology of the place.

Either way, the needs of preservation mingle inextricably to the necessities of the "new", which actually consists precisely in the very special configuration of these spaces, that appear dynamic and "contemporary" in many respects. While not being the result of a design research, these spaces act as a proper innovation in many aspects, related to the techniques of realization of the production machinery. The consequence is the particular articulation of the composing elements, renewing themselves and changing their meaning - following a long period of neglect - then giving rise to striking and evocative spaces.

The coincidence between the adjectivations "original" and "new" - that effectively overlap in the history of the productive machines - fosters a review of the concept of "authenticity" [15], which acquires a new meaning within the design process of metabolization of the change.

Starting from these considerations, work has been done on the two buildings from the point of view of the project - by identifying some factors of specificity.

In the Washery, the most crucial design tool has been found in the cross section of the rooms arranged at various altitudes, clinging to the hill and "descending" down to the sea. However, every cross section is different from the other, thus determining a situation of extreme variability, indeed, for the complex at Argentiera, we cannot speak of a building or an aggregate of buildings.

Rather, it would be more appropriate to interpret the unique architectural system which has configured itself over time as a unitary structure, based on a complex relationship between spaces of different nature and character.

On the other hand, the most impressive element of the Mill-Garden is the plan, especially the plan of the large vaulted area where the bagging operations of sulfur originally took place: a unified space - 10 meters high and 100 meters long dotted by massive supports and crossed only at its top by the pulley blocks, once carrying the material. However, this decisive role of the transport lines also characterizes the articulation of the different volumes - physically and functionally connected to each other - that somehow make it clear (especially in the interior spaces) the idea of a path that becomes architecture. 
Then, what did we thought to do to give new life to these structures? And according to what modalities have we inserted the new functions?

In either case, "the intrusion of the new" has been set - on the one hand - as a sort of frame of reference, as a new architecture aimed at facilitating the reading of the pre-existing one. But on the other hand, it has also acted for the specific purpose of involving the existing spaces into a new overall organization of the buildings.

This way, it was as though the original artefact could be "rewritten", in a logic of "superimposition" tending at creating a "multiple palimpsest". The old architecture has been thus read as a text on which to overlap new sentences, new systems, so it is inevitable introducing a different constitutive logic respect to the previous one [16].

The earlier elements have not been decontextualized, but rather reinterpreted into the new architectural machine. This new device surely has continuity with the old artefact, from which it highlighting some pieces of the original mechanism, capable of taking a new ability to function. The main design objective - not easy to achieve - has thus been focused on the internal consistency of the result. In this sense, the existing pieces qualify as the structural elements of the new composition - without taking a definitive configuration - which keeps being open to new interpretations and interventions.

\section{Building up the cognitive machine}

The project for the Washery has been defined by starting from some specific considerations about the machine-building.

Primarily, the site at Argentiera is a potential "museum of itself", meant as a document of the very peculiar productive process which started from the mines arranged at the highest altitudes - and went down to the sea, in accordance with a mechanism that can be reconstructed in precise terms, although subjected to constant changes and updates through time.

At the same time, along the structure in the opposite direction (but it is clear that this possibility emerges from the first vision of the buildings in their current configuration), the result is a sort of "adventure of knowledge", in which nothing is taken for granted, and the wonder and the surprise constitute the prevailing characterizations, namely those features which are increasingly required by contemporary architecture. The choice of crossing the architectural machine in the reverse direction is an opportunity that allows - when entering the artefact - to activate a particular cognitive mechanism, that does not follow the ordinary procedure through which a museum path is usually realized. This, just to say that the building shows an exceptional modernity in itself, and the project has strongly considered this aspect. The idea of the double path becomes even more interesting because the building is made of brick and wood: it is characterized by very traditional masonry parts, in the grounding portions; in some cases the structural wood system leans against it, other times is flanked by it. The design tries to solve and synthesize these contrasts, by working on a case by case basis and not operating any modification or appropriation of the existing structure, but 
interacting with slight grafts that appear more like an installation rather than a durable architectural intervention. The main elements of this mounting are thus: a single elevator that connects the various levels, some stairs rebuilt, some parapets of protection, and some element of exhibition design, necessary to point out the key aspects of the old machine. This aspect is aptly described by Cino Zucchi, when asserting: "The contemporary thought pursues new goals and values through a 'metamorphosis' of the existing structures. No formal adjustments a posteriori of the new compared to the existing, but rather 'grafts' able to act effectively and with insight in stratified urban contexts, (...) by grafting highly modern gems in the interstices that separate the existing layers (of the cities). (...) A graft presupposes a wound in the host organism, but also a profound knowledge of its physiology, and of the consequences implied in the transformation of an existing state, often illusorily experienced as a second nature" [17].

These installations interact with the shapes and the masses of the machinery which should be retrieved - left in their original position - and with the small and gathered facilities arranged around them. This way, significant areas of the complex (bar, reading) are entrusted with new tasks, without extrapolating them from the continuity of the spaces characterizing the whole complex (figs 5 and 6). Then the most challenging functions (conference hall, restaurant, guest house) have been settled in the two parallel volumes of the mechanical and electrical workshops, positioned outside the Washery.

In Tufo, the fundamental choice concerns the positioning of the wine museum in the wide and unified space characterized by cross pillars and large arches, arranged at the lowest level of the Mill-Garden (mentioned above as a very fascinating interior). It comes to an extremely interesting and majestic space, which can ensure a great flexibility in the organization of the exhibition and museum activities, constituting an evocative place to cross and visit.

On the upper floor, the analogous available surface has been basically divided into various support activities: the wine school, the spaces for the laboratories and for storage, and the management and administration offices. Additional spaces functionally connected to the wine museum - have been designed in the entrance building (already retrieved), and in the other buildings of the Mill-Garden, where the mining museum and auditorium have been also placed.

Even in the case of the Mill-Garden, the design work has been focused on the definition of a path that follows an opposite development compared to that of the materials. Thus, entering the large vaulted area and crossing the entire building, it is possible to reach the outdoor area, where the materials of the sulfur mine used to be deposited. It comes to parallel paths arranged at different levels in elevation, which take place at the ground level in the broad main spaces, but also higher up in side tunnels drawn amidst the building and the street, or even still higher, in a continuous exchange between the inside and the outside, also using the roofs of the lower volumes.

The configuration logic of these internal paths is the mounting of a sort of "framework", connecting all the new elements. It comes to an even temporary "support", which at the same time crosses and interprets the existing spaces, acting 


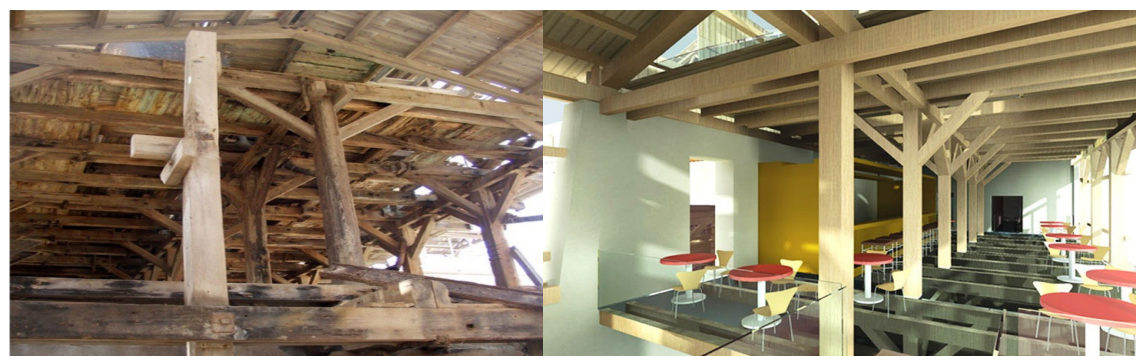

Figure 5: Current state and design for the interior spaces of the Washery.
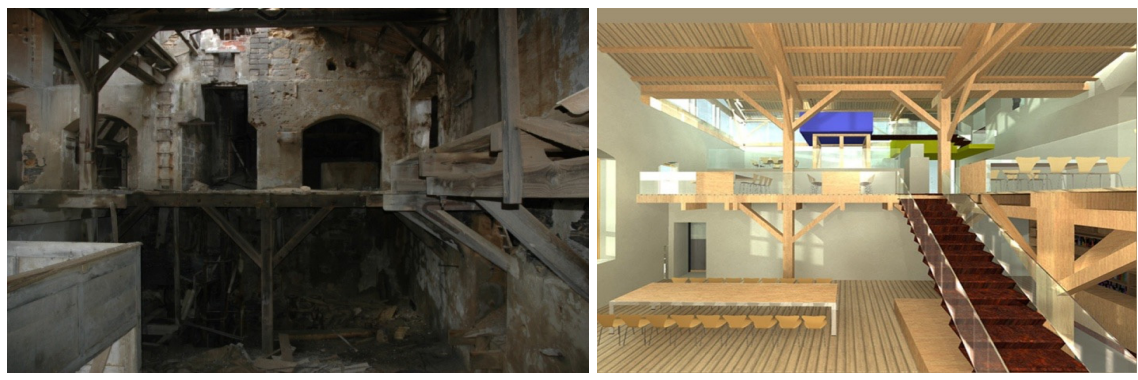

Figure 6: Current state and design for the interior spaces of the Washery.

as a sort of "installation" [18]. The result is a "performative" [19] device built on the move, configured as an "open building", thanks to the suitability of this framework to preserve degrees of freedom, by envisaging future needs and transformations in the interaction between the more "stable" parts of the composition and some variable ones [20].

The framework has therefore been meant as a sequence of connecting elements, which shapes and integrates the components of the original linkages. It is a set of absolutely necessary elements - ramps, stairs and elevators - that is to say the connection system, reunified and made functional.

In some cases - referring back again to the past of the building - the framework becomes a walkway-gallery differently configured, also recovering the interesting pre-existing footbridges, allowing to admire the interior of the wine museum from above. In yet other cases, the framework becomes the linear bar counter, which follows the whole length of the large hall and then goes on by recovering the route of the railway tracks, which originally crossed the structure completely. In short, the framework puts together different levels, and thus enables to connect the most meaningful spaces of the Mill Garden (figs 7 and 8).

\section{Conclusions}

The projects for the two abandoned productive machines in Sassari and Tufo turned into museums - allow a certain grade of indeterminacy, which brings them 


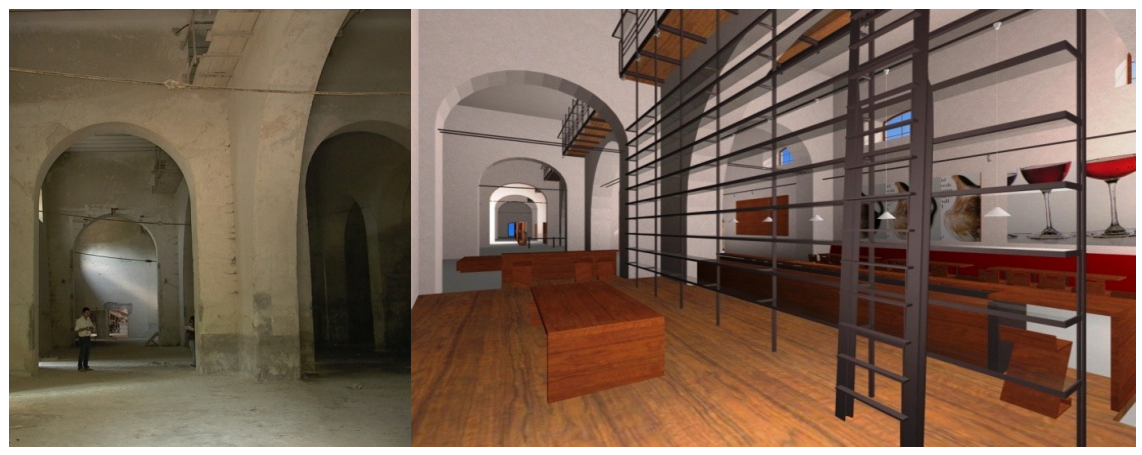

Figure 7: Current state and design for the interior spaces of the Mill-Garden.

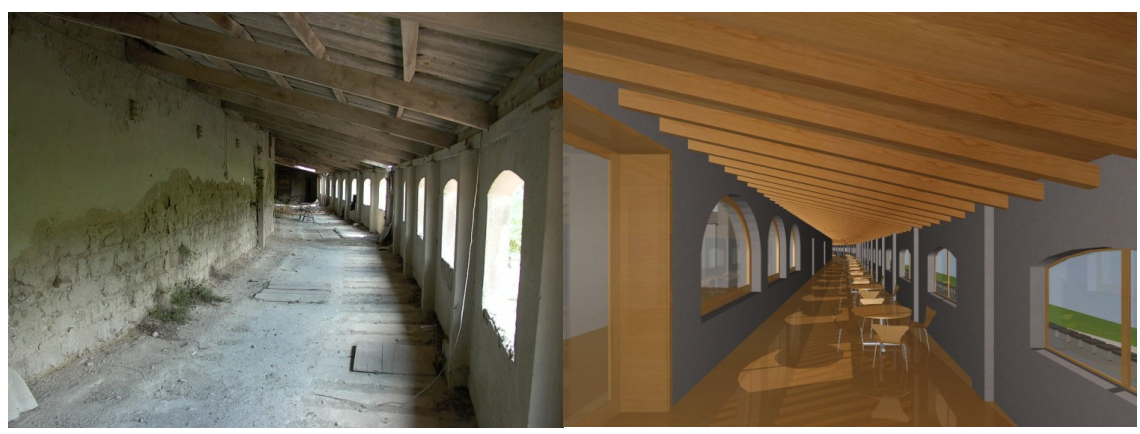

Figure 8: Current state and design for the interior spaces of the Mill-Garden.

closer to the new generation structures for the production: without being stuck in a predetermined function, they are open to a variety of uses, to a continuous changeability of the spaces at different times. Rates from this conception - in which the specificity of the machine has been called back into play, although deeply "actualized" - the project has been focused on the overlapping of a constellation of different interventions: not by redesigning the individual areas, but mostly by acting on the connections among them. Through the definition of this connective system, the "relics" of the industrial manufacturing past have been transformed into new territorial machines: active and dynamic, not least because imperfect in their hybridization of different times and uses.

Ultimately, this ambiguity inherent into the design strategies binds also to the proper character of the "eras" of these artifacts: the productive memory held by the buildings as a sense of rootedness to the site and to the landscape - together with the unexpected and perhaps transitory presence of new connecting elements, able to open new scenarios - may project the ruins of the no longer functioning machines towards the future. 


\section{References}

[1] Eisenman, P., Martin, R., Ockman J., Tschumi, B. (eds). Ruins of Modernity: The Failure of Revolutionary Architecture in the 20th Century, Exhibition at the Kimmel Center, New York City, February $7^{\text {th }}, 2013$.

[2] Aquilar, G., Ruins of Modernity and sincopated sequences. Transformation devices for the places of abandonment in Water-Edge Cities. Cities between Land and Water, eds. P. Miano, M. Russo, Clean: Naples, pp. 166-185, 2014.

[3] Miano, P., Vita e attesa di due edifici macchina. Sul futuro dell'origine. Novità ed originalità in architettura, ed. C. Di Domenico, Il melangolo: Genoa, pp. 171-178, 2014.

[4] Miano, P., Una nuova vita in edifici-paesaggi abbandonati: la Laveria a Sassari e il Mulino Giardino a Tufo, Armature tematiche e progetti, Clean: Naples, pp. 31-48, 2012.

[5] Bangstad, T.R., Industrial Heritage and the Ideal of Presence. Ruin Memories: Materialities, Aesthetics and the Archaeology of the Recent Past, eds. B. Olsen, P. Pétursdóttir, Routledge: London - New York, pp. 92-106, 2014.

[6] Edensor, T., Waste Matter - The Debris of Industrial Ruins and the Disordering of the Material World. Journal of Material Culture, 10(3), pp. 311-332, 2005.

[7] Koolhaas, R., Surrender. $S, M, L, X L$, The Monacelli Press: New York, p. 974, 1995.

[8] Landzelius, M., Commemorative Dis(re)membering: Erasing Heritage, Spatialising Disinheritance. Environment and Planning D: Society and Space, 21, pp. 195-221, 2003.

[9] Hetherington, K., Secondhandedness: Consumption, Disposal and Absent Presence. Environment and Planning D: Society and Space, 22, pp. 157-73, 2004.

[10] Marini, S., Nuove terre. Architetture e paesaggi dello scarto. Quodlibet: Macerata, p. 134, 2010.

[11] Cacciari, M., Un ordine che esclude la legge. Casabella, 14, pp. 498-499, 1984.

[12] Marini, S., Le ali dell'architettura. Spazi del lavoro ed altre alchimie. L'architettura degli spazi del lavoro. Nuovi compiti e nuovi luoghi per il progetto, Quodlibet: Macerata, p. 23, 2013.

[13] Savi, V., Nuovo Teatro Carlo Felice, Genova: Ignazio Gardella, Aldo Rossi. Domus, 719, pp. 33-49, 1990.

[14] Branzi, A., Modernità debole diffusa. Il mondo del progetto all'inizio del XXI secolo, Skira: Milan, p. 117, 2006.

[15] Agamben, G., La potenza del pensiero, Neri Pozza Editore: Vicenza, p. 309, 2005.

[16] Tschumi, B., Walker, E., Tschumi on Architecture. Conversations with Enrique Walker, The Monacelli Press: New York, p. 117, 2006. 
[17] Bocchi, R., Il futuro delle città: fra rigenerazione rammendo innesto e riciclo. Lecture at the Conference Rigenerazione, Riqualificazione, Riuso, Trentino School of Management, Trento, October 30th, 2014.

[18] Cascaro, D., Le musée décontracté. Une installation des Lacaton Vassal au Palais de Tokyo, 2006, Online. http://www.lacatonvassal.com/data/ documents/20110228-233538Int\%C3\%A9gral\%20cascaro\%20LV.pdf

[19] Lobsinger, M.L., Cedric Price. An Architecture of the Performance, Daidalos, 74, p. 24, 2000.

[20] Habraken, J.N., Supports. An Alternative to Mass Housing, Scheltema \& Holkema N.V.: Amsterdam, 1961. 